\title{
Conjunctival swabbing for the isolation of TRIC agent (Chlamydia)
}

\author{
S. DAROUGAR AND BARRIE R. JONES
}

Institute of Ophthalmology, University of London

Conjunctival scraping has been the standard method of collection of specimens for isolation of TRIC agent.* However, in spite of good instrumentation, even in the hands of experienced workers, conjunctival scraping commonly causes moderate or severe irritation, some bleeding, and conjunctival reaction, especially in acute or subacute conjunctivitis, and intensifies the patient's discomfort. It is therefore desirable to find an alternative and simpler method which would ensure a proper collection of specimens with minimal harm to tissues.

Swabbing the conjunctiva has been used for isolation of TRIC agent by Tang, Huang, Chang, and Wong (1957, I 958), Collier and Sowa (1958), Collier, Duke-Elder, and Jones (1958), and Gear, Cuthbertson, and Ryan ( $19^{6} 7$ ), but the technique has not come into general use.

The purpose of this study was to investigate the efficiency of swabbing for the collection of specimens from the conjunctiva for the isolation of TRIC agent in comparison with a standard technique of scraping.

\section{Methods and materials}

SELECTION OF CASES

Specimens used in this study were collected in cases suggestive of TRIC infection of the eye; in some cases TRIC inclusion bodies had already been observed in conjunctival scrapings.

COLLECTION OF SPECIMENS

The conjunctiva was anaesthetized by 3-4 drops of Jocaine (Cocaine hydrochloride $4 \mathrm{~g}$., adrenaline acid tartrate $0.15 \mathrm{~g}$., sod. metabisulphite $0.1 \mathrm{~g}$., neomycin sulphate $0.5 \mathrm{~g}$., chlorhexidine acetate $0 . \mathrm{I}$ per cent. $5 \mathrm{ml}$, , distilled water to $100 \mathrm{ml}$.).

Scraping Conjunctival scrapings were collected using sterile Kimura platinum spatulas or sterile aluminium scrapers which were flattened at both ends. The collected material was suspended in $\mathrm{I} \cdot 4 \mathrm{ml}$. of $2 \mathrm{SP}$ medium with antibiotics $(\mathrm{M} / \mathrm{I} 5$ phosphate buffer at $\mathrm{pH} 7 \cdot 2$ with sucrose $0.2 \mathrm{M}$, streptomycin $50 \mu \mathrm{g} . / \mathrm{ml}$. and vancomycin $100 \mu \mathrm{g} . / \mathrm{ml}$.) in a screw-capped bottle containing a few glass beads.

Swabbing Conjunctival swabbings were collected with disposable sterile culture swabs (Stayne Laboratories Limited, High Wycombe, Bucks); one dry swab was used for each eye. The conjunctival surface was wiped firmly three or four times; the swab was then placed in a screw-capped bottle containing ${ }_{2} \mathrm{SP}$ with antibiotics and a few glass beads, the stick being broken short.

Received for publication March 30, $197 \mathrm{t}$

Address for reprints: Prof. B. R. Jones, Department of Clinical Ophthalmology, Institute of Ophthalmology, Judd St., London, WC. 1 H 9 QS

*Collier (r 959), Hanna, Thygeson, and Jawetz (1959), Jones, Collier, and Smith (1959), Bernkopf, Nishmi, Maythar, and Feitelberg (1959), Perret and Mann (1960), Hanna, Jawetz, Thygeson, and Dawson (1960), Tarizzo (I961), Hanna (I962), Murray, Guerra, Abbott, and McComb (1962), Mordhorst (1964, 1965a, 1965b, r967), Sowa, Sowa, Collier, and Blyth (1965), Dawson and Schàchter (1967), Gordon, Harper, Quan, Treharne, Dwyer, and Garland (1969) 
In this study, swabs and scrapings were collected separately from different areas of the conjunctiva i.e. upper tarsus, upper fornix, and lower lid, and each specimen was cultured separately. Thesê specimens were kept at $+4^{\circ} \mathrm{C}$. for 2 to $3 \mathrm{hrs}$ until transferred on wet ice to the laboratory where the were stored at $-70^{\circ} \mathrm{C}$. until cultured.

A total of fifty specimens was collected by each method of collection. In 25 cases, swabbings were collected before scrapings; in the remaining 25 cases the order of collection was reversed.

CELL CULTURE

A simplified irradiated McCoy cell culture technique employing a one passage system was used i this study.

Monolayers of irradiated McCoy cells were prepared by the technique of Gordon and otherw (1969). Clinical specimens were shaken on a Whirlimixer for I min. and then subjected to indireç大 sonication (modified Dawe Soniprobe, Model I $130 \mathrm{~A}$, operating at a peak output of $200 \mathrm{~W}$ ) for 7 min To this specimen was added $1 \mathrm{ml}$. of fresh complete medium with additional glucose and antion biotics (CMGA: Gordon and others, 1969). The specimen was inoculated into two tubes containing. monolayers of irradiated McCoy cells. The tubes were then centrifuged at 2,700 G. for I hr. in 死 MSE Super Minor Centrifuge.

The medium in the tubes was replaced by fresh CMGA 2 hrs after centrifugation. At approxit mately $6 \mathrm{hrs}$ after inoculation the medium was removed from one tube, and the cells were washed several times with phosphate buffer and fixed for Io $\mathrm{min}$. by the addition of methyl alcohol. Th\& monolayers were stained with Giemsa's stain (Gordon and others, 1969).

Using a Zeiss RA microscope, Giemsa-stained coverslips were screened for the presence of inclusio bodies using $\times 16$ objective and optovar $\times 1 \cdot 25$ with darkfield illumination.

With 35 positive specimens, the number of inclusions in the first tube was estimated by counting the number of inclusions in ten to twenty fields. In the other forty positive specimens, the frequency of inclusions in the first tube was estimated as + to ++++ , i.e. $+=\mathrm{I}$ to Io inclusions per covers $++=$ I I to $100,+++=$ IOI to 1,000 , and $++++=$ over 1,000 .

If the first tube was negative, the second tube was fixed and stained with Giesma not later than $72 \mathrm{hrs}$ after inoculation and examined for the presence of inclusions. If the first tube was positive the second was harvested and stored for further studies.

Close attention was given to the prevention of accidental cross-infection between specimeney (Gordon and others, 1969). One coded uninfected dummy isolation specimen was included a irregular intervals as a control for every ten specimens.

\section{Results}

Positivity of cultures of material collected by swabbing or scraping

Of fifty specimens collected by scraping, 37 (74 per cent.) were positive in cell culture fơ Chlamydia : of fifty specimens collected by swabbing, 38 ( 76 per cent.) were positive (Table I)

Table I Results of cultivation of swabbings and of scrapings of the conjunctiva for the isolation of TRIC agent

\begin{tabular}{|c|c|c|c|c|c|}
\hline \multirow{3}{*}{ No. of specimens } & & \multicolumn{4}{|c|}{ Positive } \\
\hline & & \multicolumn{2}{|c|}{ By swabbing } & \multicolumn{2}{|c|}{ By scraping } \\
\hline & & No. & Per cent. & No. & Per cent. \\
\hline $\begin{array}{l}\text { Swabbing first } \\
\text { Scraping first }\end{array}$ & $\begin{array}{l}25 \\
25\end{array}$ & $\begin{array}{l}25 \\
13\end{array}$ & $\begin{array}{r}100 \\
52\end{array}$ & $\begin{array}{l}25 \\
12\end{array}$ & $\begin{array}{r}100 \\
48\end{array}$ \\
\hline Total & 50 & 38 & 76 & 37 & 74 \\
\hline
\end{tabular}


Positivity in relation to the order in which specimens were collected

During the first section of this study swabbings were collected before scrapings; this series of cases included many that were already known to be inclusion positive and there was an overall high rate of positivity. Thus all of 25 swabbings collected before scrapings were positive and all of 25 scrapings collected after swabbing were also positive.

During the second section of this study scrapings were collected before swabbings. In this series of less selected cases twelve out of 25 scrapings collected before swabbing were positive and thirteen of the swabbings collected after scraping were also positive (Table I). Thus the second collection was just as often positive regardless of whether the first collection was by scraping or swabbing.

\section{Number of inclusions in first passage in cell culture}

The number of inclusions detected in cells inoculated with material collected by swabbing, compared with those detected in cells inoculated with material collected by scraping, is shown in Table II. In each case more inclusions were present in the culture inoculated with swabbings. In the five cases in which swabbings were collected first, the total yield of inclusions by swabbing was 1,503 as compared with 95 inclusions by scraping (Table II). In the other twenty positive cases in this group, in which the frequency of inclusions was recorded as + to ++++ , the yield by swabbing was always + to ++ higher than that by scraping. In thirteen positive cases in which swabbing was collected after scraping, the total yield of inclusions by swabbing was 39,776 as compared with 10,625 by scraping (Table II).

Table II Number of inclusions in cell cultures inoculated with either swabbings or scrapings of conjunctiva

\begin{tabular}{|c|c|c|c|c|}
\hline \multirow{2}{*}{$\begin{array}{l}\text { Cell culture } \\
\text { code number }\end{array}$} & \multicolumn{3}{|c|}{ No. of inclusions* } & \multirow[b]{2}{*}{ Order of collection } \\
\hline & Swabbings & Scrapings & $\begin{array}{l}\text { Ratio } \\
\text { swabbing/scraping }\end{array}$ & \\
\hline 1 398-1 399 & 65 & 2 & $30: 1$ & Swabbing first \\
\hline $1400-1401$ & 1,000 & 27 & $30: 1$ & \\
\hline $1402-1403$ & 252 & 8 & $30: 1$ & \\
\hline $1406-1407$ & 104 & 16 & $5: 1$ & \\
\hline $1408-1409$ & 82 & $4^{2}$ & $2: 1$ & \\
\hline Total & 1,503 & 95 & & \\
\hline $1683-1684$ & 7 & o & - & Scraping first \\
\hline $1705-1706$ & 610 & 400 & $1 \cdot 5: 1$ & \\
\hline $1716-1717$ & 630 & 160 & $4: 1$ & \\
\hline $1718-1719$ & 9 & 4 & $2: 1$ & \\
\hline $1754^{-1} 755$ & 3,500 & 1,600 & $2: 1$ & \\
\hline $1756-1757$ & 3,260 & 600 & $5: 1$ & \\
\hline $1758-1759$ & 4,100 & 860 & $5: 1$ & \\
\hline $1762-1763$ & 2,720 & 1,720 & $1.5: 1$ & \\
\hline $1764-1765$ & 4,140 & 1,320 & $3: 1$ & \\
\hline $1766-1767$ & 5,600 & $\mathbf{1}, 320$ & $4: 1$ & \\
\hline $1746-1747$ & 600 & 8 & $75: 1$ & \\
\hline $174^{8}-1749$ & 1,600 & 33 & $50: 1$ & \\
\hline $1750-1751$ & 13,000 & 2,600 & $5: 1$ & \\
\hline Total & 39,776 & 10,625 & & \\
\hline
\end{tabular}

* Number of inclusions in one cell culture monolayer at first passage 


\section{Discussion}

In view of the 4 -fold number of inclusion bodies found in cultures inoculated with materia collected by swabbing $(41,279)$ as compared with material collected by scraping $(10,720)$, it is surprising that there was so little superiority of swabbing over scraping when compared on the basis of the number of positives $(38: 37)$, even though each pair of specimens $\Rightarrow$ compared came from only one area of conjunctiva of one eye, viz. upper tarsus, uppero fornix, or lower lid. Presumably, however, the collection of material from cases that had흘 less viable TRIC agent in the conjunctiva would show a greater superiority for swabbing. It is of interest that, regardless of the order of collection by swabbing or scraping, the second $\mathbb{Q}$ specimen was just as often positive as the first.

These findings would appear to indicate that in isolation-positive cases in London, there $\vec{\circ}$ is generally enough viable TRIC agent in the conjunctiva to yield positive specimens if $\overrightarrow{\vec{\omega}}$ collection is immediately repeated. But counting or estimating the number of inclusionso in the first passage in primary isolation in McCoy cells provides a more revealing method o: assessing the quantity of viable agent collected from the conjunctiva than does a comparisoni of the prevalence of positive cultures.

Conjunctival scraping for collection of material has the following disadvantages:-

(I) An experienced collector is essential for the collection of good specimens.

(2) The use of scrapers that are damaged or of poor quality will result in the collection of poor specimens, and may increase the reaction in the eye.

(3) The process of sterilization of scrapers, collection of scrapings, and cleaning of scrapers is relatively slow and complicated, taking approximately 5 minutes per patient.

(4) In acute or subacute conjunctivitis, bleeding is a common complication of scraping The bleeding may affect the quality of the specimen and lead to neutralization of infectivity by serum antibodies.

(5) Reactions after scraping include mild or severe irritation, pain, lacrimation, photo-市 phobia, swelling of the lids, conjunctival hyperaemia and discharge, and occasionally the development of inflammatory conjunctival membranes. These side-effects often discourage patients from co-operating in serial scraping for follow-up studies or tests of cure.

(6) The term "scraping" often leads to fear and antagonism in the patient.

In this study is has been shown that conjunctival swabbing is at least as sensitive as scraping for the detection of positive cases, and the amount of cultivable TRIC agent in swabbings is greater than that in scrapings.

The other advantages of swabbing are:

(I) Simple instruction enables a relatively inexperienced technician or nurse to collecto good specimens for isolation.

(2) The use of commercially available swabs provides a simple and rapid method of specimen collection that takes approximately only I minute per patient.

(3) Swabbing rarely gives rise to bleeding.

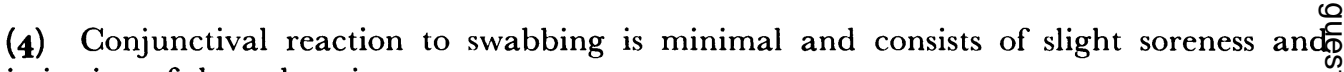
irritation of short duration. 
(5) The term "swabbing" does not frighten the patient.

The commercial swabs used in this study measured 10-1 $2 \mathrm{~mm}$. by $5^{-7} \mathrm{~mm}$. with a rounded end, and were firmly fixed on the end of wooden sticks. This size of swab usually absorbs 0.2 to $0.3 \mathrm{ml}$. of medium. The blunt end of the swab is important for the collection of specimens from the conjunctiva of the lower lid. It has been shown that swabs that have been overheated, especially in the hot-air oven, may char and give rise to tarlike products which are toxic to bacteria and may be toxic to Chlamydia; swabs for these collections should therefore be sterilized by radiation or by autoclaving (Cruickshank, 1965).

In view of all these advantages of swabbing over scraping there would seem little doubt that swabbing is the method of choice. Its adoption should significantly reduce the work involved and the discomfort sustained by the patient in the isolation of TRIC agent from the eye in field studies of trachoma or in diagnostic clinics for external diseases of the eye.

\section{Summary}

In this study, swabbing of the conjunctiva for the collection of specimens for the isolation of chlamydial agents was compared with a standard technique of scraping.

Fifty specimens collected by each method were inoculated into cell monolayers using a simplified system of irradiated McCoy cell culture; 37 (74 per cent.) were positive in specimens collected by scraping and 38 ( 76 per cent.) in specimens collected by swabbing. The number of inclusion bodies detected in cell culture was approximately 4 -fold higher from specimens collected by swabbing than from those collected by scraping.

The simplicity and speed of collection by swabbing, with freedom from the undesirable sequelae of scraping, should significantly facilitate the use of isolation of TRIC agent in field studies of trachoma, and simplify the work of diagnostic clinics for external diseases of the eye.

We are grateful to Mr. J. R. Kinnison, Mr. R. Hejazi, and Miss M. Vance for technical assistance and to Miss C. Carlyle for secretarial help.

\section{References}

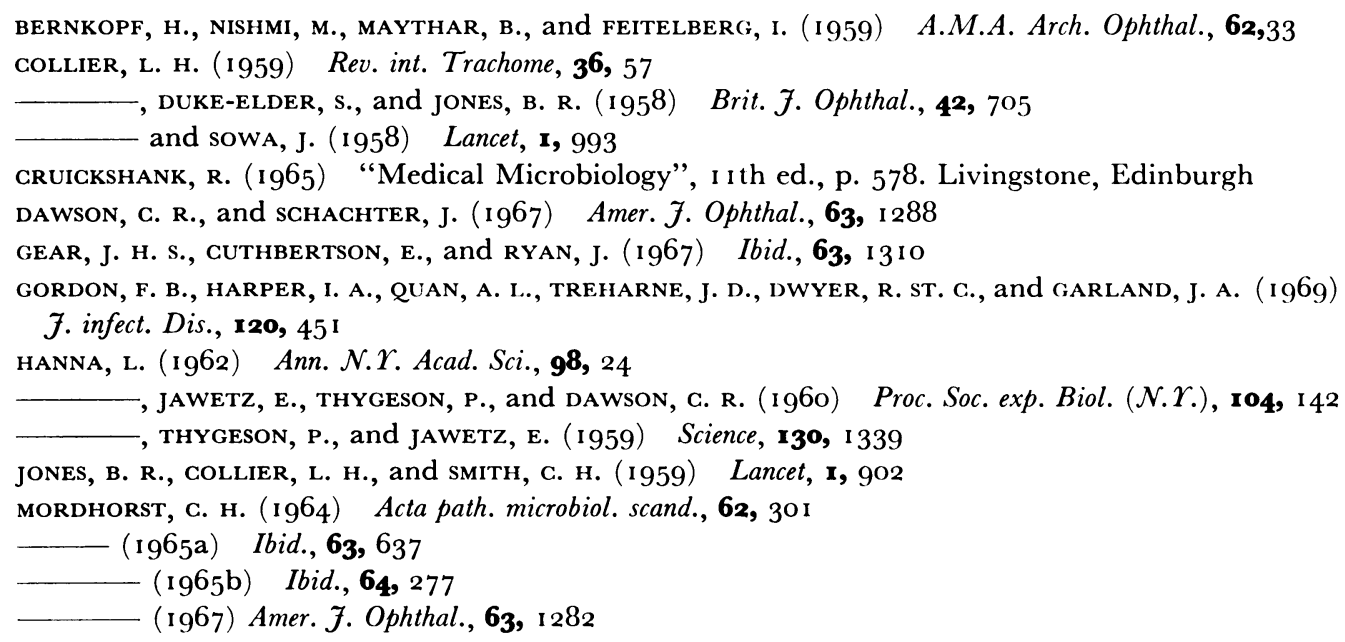




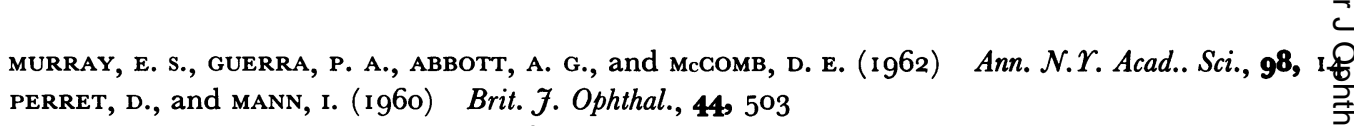

sowA, s., sowA, J., Collier, L. H., and BLYTH, v. (I965) "Trachoma and Allied Infections in

Gambian Village”, Medical Research Council, Special Report Series No. 3o8. H.M.S.O London

TANG, F.-F., HUANG, Y. T., Chang, H. L., and wong, K. c. (1957) J. Hyg. Epidem. (Praha), r, Io9 $\longrightarrow,-,-\longrightarrow$ (1958) Acta virol. (Praha), 2, 164

TARizzo, м. L. (1961) Bull. Wld Hlth Org., 24, I03 